\title{
Stage I Gallbladder Cancer AJCC v7
}

National Cancer Institute

\section{Source}

National Cancer Institute. Stage I Gallbladder Cancer A/CC v7. NCI Thesaurus. Code

C90216.

Stage I includes: T1, N0, M0. T1: Tumor invades lamina propria or muscular layer. N0: No regional lymph node metastasis. M0: No distant metastasis. (from AJCC 7th Ed.) 